\title{
Examining the Relationship between Selfies, Adolescents and Archetypes: The Psychology of Taking Selfies and their Consequences on the Adolescent Self-Conscious
}

\author{
Petro van der Merwe ${ }^{*}$
}

\author{
Department of Psychology, University of South Africa, Tshwane, South Africa
}

\begin{abstract}
This study explores the attitudes of adolescents in South Africa towards selfie-taking as well as the effects that the selfie has on the consciousness of their shadow. The aim is to contribute to understanding the current impact of this phenomenon on adolescents. Social media, through the use of selfies, can encourage self-promotion and create an obsession with one's physical appearance. Adolescents mostly shape their self-concepts based on their understanding of how others view them. The informants comprised 58 learners from three secondary schools in Tshwane (Gauteng). The data collection methods used were semistructured interviews and observation methods. This research study resonates with the looking-glass-self perspective, which highlights the importance of the evaluation of others to the development of the self-conscious. Technology constantly evolves and grows, a theoretical implication of which is the need to continue exploring selfies as a means for the search of identity. Regardless, in raising the question of what selfies, adolescents, and archetypes have in common, this article succeeds in bringing together this rather recent concept, the area of scientific enquiry related to selfies, and a psychological construct coined by the founder of analytical psychology, Jung, that is so well established in the sciences and steeped in thoughts of wisdom that it has stood the test of time. In doing so, the article taps into not only developmental psychology but also social psychology and sociology, the study of human social relationships.
\end{abstract}

Keywords: Selfies, adolescents, personal shadow, archetypal identity, self-conscious, collective unconscious.

\section{INTRODUCTION}

Owing to the relatively recent uptake of selfie practices, the impact of selfies has only recently become the subject of scientific studies (McLean, Jarman \& Rodgers, 2019). Or may selfies not be that recent, after all? Interestingly, one source purports that the man who invented the selfie was Robert Cornelius, who snapped his photo in 1839 (Brin, 2017). However, the word "selfie" was first tweeted in 2006 (Independent life-style, 2019). According to Molloy (2013), the year 2013 will always be remembered as the year of the selfie.

During the period of adolescence, selfies allow adolescents to carry out their exploration of identity in digital form (Soerjoatmodjo, 2016). Adolescence constitutes a period of identity confusion, of questioning and uncertainty, of discovery and meaning-making. The word "adolescence" comes from the Latin word "adolescere", which means to grow up or to grow into maturity (Lerner \& Steinberg, 2009). Indeed, it is a period of Sturm und Drang (Cravens, 2006). Translated, the German phrase "Sturm und Drang" means "storm and urges", or "storm and stress". It refers to a literary movement of the late 18th century that was full of idealism, commitment to a goal, a

*Address correspondence to this author at the Department of Psychology, University of South Africa, Tshwane, South Africa; Tel: +27124292118;

Fax: +27124293414; E-mail: vdmerp1@unisa.ac.za revolution against the old, and the expression of personal feelings, passion, and suffering (Hall, 1904). Unsurprisingly, Sturm und Drang is also used in developmental psychology to refer to the period of adolescence. Hall, in an impressive two-volume scientific and scholarly work that is one of the first in the field of adolescence psychology, was the first to draw an analogy between the psychological characteristics of adolescence and the Sturm und Drang movement, characterised by works containing rousing action and high emotionalism that often deal with the individual's revolt against society. The comparison may be even more apt in current times, when so many pressures challenge the identity of the teenager, including the world wide web, new technology such as the smartphone, social networking sites, and 24/7 connectivity.

My interest in this research topic originates from my research on new technology and associated psychosocial risks in adolescents, as well as my dayto-day witnessing of how the practice of taking selfies has evolved - from capturing a basic picture of oneself to applying various photographic filters to make oneself more attractive and change one's actual appearance.

The real power of the selfie can be discovered when one goes beyond the normal public expressions to capture what is not being openly expressed. Taking a candidly emotional portrait of oneself or even a nonflattering one can be very liberating (Ronning, 2015). 
Capturing and curating a multitude of these images can help to redefine how an individual sees him- or herself, to go beyond the daily roles one inhabits by cultivating creative risk-taking. This got me thinking as an academic and researcher, but also a psychotherapist, about selfies and the use of filters in striving for perfection in self-presentation, and of posting them, or not. I wondered about social comparison, selfconsciousness as opposed to self-awareness, and the skill of reflexivity; about self-and social acceptance and rejection, and the fear of rejection, and about individuation as the main task of human development, according to Jung (1947). For these reasons, the choice of Jung's theories in understanding adolescence seems most appropriate, and the sharing of my research and experiences during related community engagement, most compelling. Furthermore, relatively few selfie studies have focused on adolescents in South Africa.

\section{The Relationship between Selfies, Adolescents, and Archetypes}

Selfie-taking and -posting are some of the most popular activities among teenagers and form an important part of online self-presentation that is related to identity issues and peer relations. It would be an easy assumption to call the selfie fad narcissistic as there are quite a few selfie-obsessed people who are in love with their photogenic. However, the great divide between our superficial lives, reflected on social media, and our real lives in the material world tell me that something deeper than a fad is driving this trend something deeper than the ego or the desire to socially compete with others; something connected to all of us at the root level; something called "archetypes".

Carl Jung is a major figure when it comes to exploring the dark side of human nature as he introduced the term "personal shadow" to describe it (Jung, 1947). He describes it in two ways, namely the personal and the archetypal shadow (Jung, 1948). The personal shadow contains specific features of an individual's psyche that they block, repress, or defend themselves against because the material is both threatening and regarded as antithetical to what they wish they were. This shadow also contains the shadow of society - fed by neglected and repressed collective values. With this background, this research aimed to investigate the part of the personal shadow that links with the selfie - let us call it the "shadow selfie".

The shadow's appearance and role depend mainly on the living experience of the individual because much of the shadow develops in the individual's mind rather than simply being inherited in the collective unconscious.

\section{Concept of the Shadow}

As stated, Carl Jung is famous for formulating the concept of the shadow - that part of everyone's personality which, through the course of one's life, is relegated to the darkness of the unconscious. Jung argues that that which we do not bring to consciousness appears in our lives as fate (Goodreads, 2018).

Both the true self (also known as the "real self", "authentic self", "original self" and "vulnerable self") and the false self (also known as the "fake self", "ideal self", "perfect self", "superficial self" and "pseudo-self") are psychological concepts that are often used in connection with narcissism. The psychiatrist and psychoanalyst Donald Winnicott regards the true self as rooted from early infancy in the experience of being alive, including blood pumping and the lungs breathing, called by Winnicott the "simply being" (as cited in Jacobus, 2005 p. 160). According to Winnicott, the danger effectively lies in the creation of what he calls the "false self" - when "other people's expectations can become of overriding importance, overlaying or contradicting the original sense of self, the one connected to the very roots of one's being" (as cited in Klein, 2006 p. 241). The danger lies in the fact that "through this false self, the infant builds up a false set of relationships, and using introjections even attain a show of being real" (Klein, 2006 p. 287) while in real life, merely concealing a barren emptiness behind an independently seeming façade (Minsky, 1996 pp. 119 20).

Jungians have explored the overlap between Jung's concept of the persona and Winnicott's false self but, while noting similarities, consider that only the most rigidly defensive persona approximates to the pathological status of the false self (Jacoby, 2017 pp. 59-60). Among the central concepts of analytical psychology is individuation - the lifelong psychological process of differentiation of the self from each individual's conscious and unconscious elements (Young-Eisendrath \& Hall, 1991 p. 29). Jung considers this to be the main task of human development.

\section{Personal Shadow and "Shadow Selfie"}

At a young age, individuals learn that certain personality traits, impulses, emotions, and behaviours elicit a reproach and negative feedback from their 
family, peers, and society. This negative feedback elicits anxiety in the individual, resulting in these "negative" characteristics being relegated to the unconscious. Throughout development, these repressed characteristics of one's self coalesce to form the shadow - the "dark" side of our being (Academy of Ideas, 2015).

Given that every human being has a wide variety and range of traits, impulses, and emotions, every individual by necessity has a shadow. Some of these characteristics must be repressed and hidden, both from oneself and others - from oneself so that one can navigate through life with the conviction that one is a wholly good and virtuous human being, and from others so that one can fit in and succeed socially (Academy of Ideas, 2015).

\section{Explanation of the Selfie}

The selfie can be defined as a photograph of oneself that causes the transference of a human feeling in the form of a relationship between the viewer and the viewed, between individuals circulating the image, or between the image and filtering software (Senft \& Baym, 2015). The selfie can further be regarded as a gesture that is often intended to send different messages to individuals which can be amplified or modified by misreading the sender's original intent or adding additional gestures, such as likes or comments. Hines (2016) agrees and defines the selfie as an individualised picture of oneself that portrays beauty and attractiveness.

\section{Selfie Criminology}

Adolescents were apparently either too wrapped up in the digital world to think clearly about the real one, or so blinded by their egos that they did not recognise the law-breaking mistakes they were making. In other words, they took criminal selfies (Hanson, 2018). In Halmstad, Sweden, two teenage girls took a selfie together in a bathroom while wearing balaclavas and holding a knife. They would go on to rob a fast-food restaurant, making off with a mere $\$ 400$ before getting arrested. The cops found that selfie on one of their smartphones (Hanson). The two girls took that selfie before they robbed the fast-food restaurant, unaware of the potential ramifications of their actions; they were doing it for the thrill. That image was never uploaded to social networking sites, yet the selfie was taken during a moment of freedom and pleasure.

The selfie becomes an instrument for adolescents to have strategic control of how they present themselves to other users, which is often much easier to do than in face-to-face communication (Ellison, Heino \& Gibbs, 2006). Adolescents self-present by editing selfies (Chae, 2017) through various filters that improve their appearance (Chua \& Chang, 2016). Through the selfie, adolescents are therefore able to manage their impressions made on others and gain acceptance from their peers through likes and comments received on social media (Mascheroni, Vincent \& Jimenez, 2015; Chua \& Chang, 2016). Selfpresentation and social comparison seem to have a direct link with a negative body image and this, in turn, decreases one's self-esteem (Webster \& Tiggemann, 2003). According to Hayes, Van Stolk-Cooke, and Muench (2015), this social comparison makes young users more self-conscious and creates a desire to change certain body parts to look aesthetically pleasing.

\section{The Nature of the "Shadow Selfie"}

A "shadow selfie" is a self-portrait showing only the shadow of the photographer. This is often used by shy people who want to create a sense of mystery in their images or enhance their image and/or ego (Nicholls, 2017).

As mentioned, Jung describes the personal shadow in two ways, namely the personal and the archetypal shadow (Jung, 1948; Academy of Ideas, 2015). The personal shadow contains specific features of an individual's psyche that they block, repress, or defend themselves against because the material is both threatening and regarded as antithetical to what they wish they were (Diamond, 2012). Therefore, the Jungian shadow can include everything outside the light of consciousness and may be positive or negative. Jung refers to the shadow as the unknown dark side of the personality (cited in Diamond, 2012).

With intention, the "shadow selfie" can be even more. It can expand the image of one's self by providing a means to explore a depiction of one's identity: a former identity, a transitional identity, a hoped-for identity, or even an imaginal or archetypal identity. The effects can be immediate. In Jungian psychology, archetypes are highly developed elements of the collective unconscious (Jung, 1948). Being unconscious, the existence of archetypes can only be deduced indirectly by examining behaviour, images, art, myths, religions, or dreams. These images and motifs are more precisely called archetypal images (Jung, 1948). 


\section{Making the Shadow Conscious}

Jung implores people to know their shadow, stating that "everyone carries a shadow, and the less it is embodied in the individual's conscious life, the blacker and denser it is" (Jung, 1969 p. 131). Finding meaningful and contained ways to express your shadow can prevent it from coming out in more selfdestructive or dangerous ways. Anyone who has dressed up as an evil character for a fancy-dress party knows it is fun to express dark impulses. What forms does your shadow take? Vampires and zombies are shadow archetypes (Martin, 2015). Vampires represent immortality gained by siphoning the life force of others. Zombies represent a lack of awareness, having turned themselves over to the lower forces - forces which in real life can include anything from impersonal corporate credos to unapologetic self-absorption (Martin).

Jung describes the shadow as a denied part of the self, a part we repress because we have been given a message that it is "bad" or "evil", or that we need to feel shameful or guilty about if we have it (Rad, 2011). Can we see the selfie as a valuable tool for self-exploration and expression?

This brings us to the fundamental fact that the shadow is the door to our individuality. In as far as the shadow renders us our first view of the unconscious part of our personality, it represents the first stage toward meeting the self.

The selfie is ubiquitous in social media. Propelled by the ever-present smartphone, most of these digital self-portraits are casual, spontaneous, and off the cuff -taken at arm's length. Some researchers and the mainstream press have linked the selfie with narcissism; someone even coined the term "selfie syndrome" (Ronning, 2017; Barry, Doucette, Loflin, River-Hudson \& Herrington, 2015). Conversely, we can also see it as a new visual genre - a type of selfportraiture formally distinct from all others in history. More than any other time in history, wrestling with the shadow is prime time activity. The shadow recedes, and the self of higher awareness shows up.

\section{Selfie Experimentation}

Adolescents between the ages of 15 and 18 post more selfies on social media than other generational groups, according to a survey by Glum in 2015. Social scientists lump selfies as prevalent among today's adolescents (Sifferlin, 2013). However, let's face it, selfies are not just for adolescents; almost everybody who has a smartphone is participating in the selfie craze. Former United States President Barack Obama, former British Prime Minister David Cameron, and former Danish Prime Minister Helle Thorning-Schmidt caused an uprising on social networks when they were seen taking a photo of themselves during Nelson Mandela's memorial service (BBC News Magazine, 2013). We, therefore, live in a world where selfies are taken everywhere, cluttering our cameras, text messages and social media news feeds. Moreover, whether we loathe this steady stream of photos or are guilty of snapping one too many ourselves, we all must think twice about the power of these pictures.

New research shows that capturing your image on camera does good things for your confidence levels, with regular selfie-snappers reporting that they feel more attractive and liked than those who do not selfie at all (Chua \& Chang, 2016; Park, Kim, Shon \& Shim, 2013). Regularly taking a photo of yourself could be the easiest way to give yourself an instant confidence boost.

In a study led by Daniel $\mathrm{Re}$ at the University of Toronto's Department of Psychology, researchers asked 198 college students, 100 of whom reported being regular selfie-takers, to snap a selfie with a smartphone, as well as pose for a photo taken by another person (Re, Wang, He \& Rule, 2016). Afterward, the students rated both photos based on how they believed their friends would interpret the images if they were posted on social media. A separate group, made up of 178 members of the public, were also asked to rate the images.

Both the selfie-takers and the non-selfie-takers thought they would be seen as more attractive and likable in the photos they snapped of themselves. Interestingly, the selfie-takers overwhelmingly overestimated their attractiveness and likability compared to the non-selfie-takers (Re et al., 2017). In other words, those who regularly snap selfies think they look (and will be liked) better than those who do not take photos of themselves.

While the selfie-takers thought that they would be perceived as more attractive and likable in their selfies, that was not the case. The public preferred the photos taken by other people over the selfies snapped by both the selfie-takers and non-selfie-takers. The public also went so far as to say that the participants were less attractive, less likable, and more narcissistic in their selfies than in the photos taken by others ( $R e$ et al., 2017). 
Bold (2016) thinks that self-enhancing misperceptions may support selfie-takers' positive evaluations of their selfies, revealing notable biases in self-perception. This further confirms that individuals find selfies more attractive as they become more familiar with them.

Jung claims that he has identified a large number of archetypes, among which is the "persona" (or mask) as the outward face that we present to the world (Jung, 1947). It conceals our real self, which Jung describes as the "conformity" archetype (Jung, 1948). This is the public face or role that a person presents - as an actor - to others as someone different from whom we are. Another archetype is the shadow. This is the animal side of our personality (like Freud's id) (Jung, 1948). It is the source of both our creative and destructive energies. In line with the evolutionary theory, it may be that Jung's archetypes reflect predispositions that once had survival value (Jung, 1948). Finally, there is the self that provides a sense of unity in experience (McLeod, 2014). Since Freud divides the powers of agency between ego, superego, and id (if indeed the id can be said to have agency), an overall self is absent, having an agency that is more than conscious. "Agency" refers to the human capacity to influence one's functioning and the course of events by one's actions (Lamia, 2010). Agency, therefore, relates to autonomy and will.

Jungians can get a bit idealised about this with talk about "the self knows", but there are certainly many occasions when a purposive direction and agency emerge into consciousness quite beyond the ego's previous awareness. I, therefore, like it when Jung talks about the self as the "spiritus rector" and uses analogies like the ego being moved about by the self like a piece on a chessboard (as cited in McGuire, 1974 pp. 115-116). For Jung, the ultimate aim of every individual is to achieve a state of selfhood (similar to self-actualisation), and in this respect, Jung (like Erikson) is moving in the direction of a more humanist orientation (McLeod, 2014). Hence greater integration and individuation (as Jung reminds us) inevitably lead to greater humility and a richer sense of the limits of our knowledge and power.

Selfies can provide self-affirmation and identity (Ellison, Heino \& Gibbs, 2006). Being able to look at yourself and say: "This is who I am, and this is what I look like and that is OK," is an incredibly helpful part of building an identity that is secure and self-defined. Selfies give people a chance to feel in control of how they present themselves to the world, and selfies can help with the human connection. Selfies became a global phenomenon due to our very human, very normal desire to see ourselves as others might see us. The popularity of the selfie is, according to Mariann Hardey, an extension of how we live and learn about each other and a way of imparting necessary information about who we are (Hardey, 2015).

\section{The Goal of the Study}

With this background, this research aims to explore how selfies impact adolescents' well-being and consciousness of their shadow. The study was guided by the following question: What effect does the selfie have on the degree in which adolescents are conscious of their shadow?

\section{METHOD}

\section{Research Design}

Convenience sampling was used, as I administered the research in Tshwane (Gauteng) at three public secondary schools. The method of data analysis used for this research was interpretative phenomenological analysis (Pietkiewicz \& Smith, 2011), intending to explore in detail how adolescents make sense of their selfie experiences. Qualitative data methods are mainly focused on gaining insights, reasoning, and motivations, therefore quantitative analysis was also used to quantify attitudes, opinions, behaviours, and other defined variables (see Table 2).

\section{Sample Selection}

Social media was used to recruit potential participants. A post was uploaded using each school's private Facebook page. The post stated the following: "I am a psychologist who is currently undertaking a research study. The research I am undertaking will involve adolescents. The study will aim to explore and describe the psychological effects of selfies. Persons interested in being part of the study have to be within the age range of 15-18 years and take a selfie at least once a week. Please contact us to obtain further information."

When interested adolescents responded, I sent them a letter that contained further details regarding the research and an informed consent form. If an adolescent agreed to participate in the study, an interview was arranged. The interviews took place at the participating schools. 


\section{Data Collection}

The data collection methods used were semistructured interview questions and observation methods.

\section{Semistructured Interview}

The interview format was storytelling, which is the process of sharing facts with emotions and details. This format allowed me to probe and clarify the participants' experiences of selfie-taking. Of course, it can also be helpful to come to the story interview prepared with some questions. You may not follow them exactly or even ask all of them, but they can help you gather key facts during the interview. The participants were notified of this schedule at the beginning of the interview and informed that it would not restrict the interview questions, but could be a helpful guide. The questions in the interview schedule were guided by the general aims of the research.
The questions were framed by me and validated by the Ethics Committee of the Department of Psychology at Unisa. The scale was administered to a general population of 5 subjects to test the clarity of the questions. Unclear questions were then reframed, and the final interview questions were administered to the adolescents in the study. The semistructured interview schedule had a total of 10 questions and was in English only. Table 1 contains the schedule that guided the interviews.

\section{Observation Methods}

The observation involved viewing selfies posted by the participants in the previous three months (January 2020 - March 2020) on the social networking sites Facebook and Instagram. It allowed me to observe a real-life situation of how each adolescent edited and responded to peer comments on a selfie. This was the most natural way to view how the participants reacted

\section{Table 1: Interview Schedule that Guided the Interviews}

\section{If you were to tell me a story about your selfie-taking, where would you begin?}

To help you decide how to describe your selfie-taking, consider the following questions:

1. As briefly as possible, tell me why do you take selfies?

- How often do you take a selfie?

- When you do not take selfies, do you feel detached from your peer group?

2. Are selfies art?

- Do you think that taking different selfie poses helps increase your social status?

- Do you take selfies as trophies for future memories?

- Do you think that taking selfies provides better memories about the occasion and the experience?

3. Do you use a filter on your selfies?

- Do you use photo-editing tools to enhance your selfies to look better than others?

4. How long does it take for you to take a selfie?

- Do you think it reduces your stress level by taking selfies?

- Do you gain more acceptance among your peer group when you take selfies and share them on social media?

5. Can you please rate your usual level of self-esteem (out of 10 ).

6. Rate your level of self-esteem during a selfie sitting (out of 10).

- Does taking selfies instantly modify your mood?

- Do you take more selfies and look at them privately to increase your confidence?

- If you take more selfies, does it improve your mood and make you feel happy?

- Do you become more positive about yourself when you take selfies?

- Do you express yourself more in your environment through selfies?

- Do you think that sharing your selfies creates healthy competition with your friends?

7. Where do you post your selfies?

- Do you post selfies frequently to get more "likes" and comments on social media?

- $\quad$ By posting selfies, do you expect your friends to appraise you?

8. Does taking selfies to give you a good feeling to better enjoy your life as an adolescent?

9. Do you post selfies because you want people to make you feel better about how you look?

- Does that selfie you are posting show who you are? Or are you filtering and editing it to make yourself look like someone you are not?

- Do you post selfies because you are feeling anxious or depressed?

10. What would you like me to know about what you are and what you do that I have not asked? 
to comments or "likes" on their own posted selfies or the selfies of their peers.

A total of 58 adolescents $(n=58)$ participated in this research.

\section{Procedure}

Approval to conduct the research was obtained from the Gauteng Department of Education and approval was sought from the principals and governing bodies of the participating schools. A parent or a guardian was also required to give consent before an adolescent learner could take part in the study. When adolescent learners chose not to take part or did not provide a parental consent form, no statement they made was included in the data. Ethical approval was obtained from the Research Ethics Committee at the University of South Africa (record number PERC-16019).

\section{Strategies for Ensuring Trustworthiness}

To ensure the trustworthiness of the research, the criteria proposed by Berg (2009) were used. According to Berg, reliability depends on accuracy, which is attempted by continuous checks and rechecks for data accuracy with the help of other researchers. Regarding validity, as also suggested by Berg, the data were analysed with the help of colleagues at the Department of Psychology as peer reviewers. To ensure credibility, all interviews were conducted by me. The transcription process was also done by me, during which I developed a familiarity with the content of the data. Each interview transcript was co-scrutinised, peerexamined, and reviewed for accuracy by the peer researcher. Concerning the corroboration of findings, I did a preliminary presentation of my findings to the peer researcher, who gave her input concerning further interrogations of the data.

Transferability was achieved by putting what participants expressed to me into the context of the surrounding social environment of the research study. This will allow outside researchers and readers to make the transferability judgements themselves.

Dependability and confirmability were assured by an inquiry audit of evidence of the following records that are in my safekeeping: interview responses, verbatim transcripts, research-related process notes, and feedback recommendations. I also consulted the peer researcher regularly during the research process to ensure that researcher bias did not skew the interpretation of what the research participants had said.

\section{RESULTS AND DISCUSSION}

\section{Results}

Based on the data gathered, the findings of this research are presented below, based on details regarding participants and their responses. The characteristics of the participants sampled in this research are as follows:

The majority of the research participants were 15year-old secondary school adolescents, as shown in Figure 1. The mean ages for males and females were 15.4 and 15.7 years respectively.
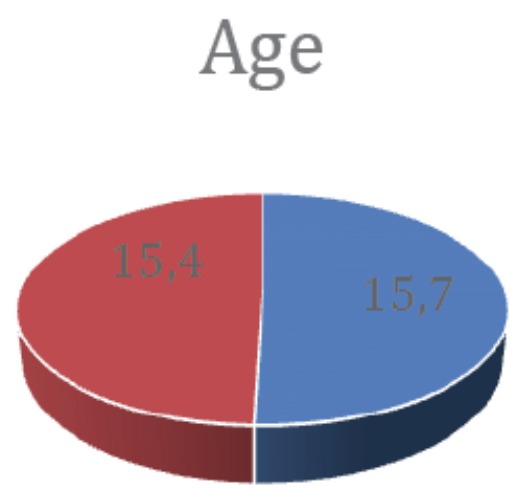

\section{- Males - Females}

Figure 1: Age of the research participants.

As can be seen in Figure 2, out of a total of 58 participants in this research, $54 \%$ were female adolescents and $46 \%$ were male adolescents.

\section{Gender}

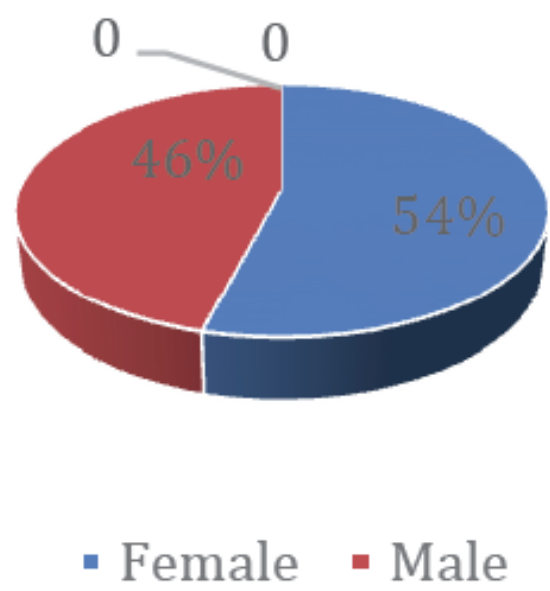

Figure 2: Gender of the research participants. 
The difference between the genders concerning the frequency of taking selfies was not statistically significant. On examining the type of smartphones used, it was observed that $6.82 \%$ of the participants had expensive iPhones, while the rest used other smartphones.

The results of the entire group who participated are now provided. I think that the small number of participants per school is not a defensible sample for evaluation, therefore the results are not delineated per school. The data were analysed using NVivo 11 to aid in coding and organise emergent themes. Analysis in an interpretative phenomenological approach is said to be "bottom-up". This means that I generated codes from the data, rather than using a pre-existing theory to identify codes that might be applied to the data. This approach encouraged an open-ended dialogue between me and the participants and therefore led us to see things in a new light.

In preparing the findings report, I was looking for evidence of the benefits and drawbacks of selfies based on the idea that the shadow does not only contain destructive and evil aspects of the personality, but also potent, creative, and powerful capabilities. Interpretative phenomenological research studies do not test theories, but they are often relevant to the development of existing theories.

Quantitative analysis is used to quantify the problem by way of generating numerical data or data that can be transformed into usable statistics. Qualitative data is used to capture expressive information not conveyed in the quantitative data, in this study, about beliefs, values, feelings, and motivations that underlie selfietaking behaviours.

The main themes emerging from the answers provided by the participating adolescents are captured in Table 2. The percentages of answers which best illustrate the themes identified are provided.

The above-mentioned percentages reflect that developmentally, selfies make sense for adolescents. The adolescents' attitudes indicate that selfie-taking, with or without the intention to share selfies on social media, is very common among adolescents. Moreover, for the most part, these are simply reflections of their self-exploration, and nothing more. The average frequency of taking selfies was higher than that of posting selfies, although this difference was not tested with inferential statistics. Should this discrepancy be formally tested and confirmed in future studies, it may be that this ratio would reflect low confidence in sharing selfies on social media, or concerns about appearance. The suggestion that adolescents may be concerned about sharing selfies online is also supported by Dutta's finding that only $30.4 \%$ of adolescents feel confident while posting their selfies online (Dutta, Sharma, Dikshit, et al., 2016).

Self-captured images allow adolescents to express their mood states and share important experiences. As adolescents try to form their identity, selfies serve as a way to test how they look and therefore feel in certain

Table 2: Themes Emerging from Adolescents' Answers Regarding their Attitudes Towards Selfies

\begin{tabular}{|c|c|}
\hline Theme & Percentage \\
\hline Took selfies regularly & $88.0 \%$ \\
\hline Approved of others taking selfies regularly & $88.5 \%$ \\
\hline Took more than four selfies per day & $62.3 \%$ \\
\hline $\begin{array}{c}\text { Used three or more social network platforms, such as Facebook, Instagram, WhatsApp, and Snapchat, to post their } \\
\text { selfies }\end{array}$ & $79.5 \%$ \\
\hline Edited their selfies "very often", using software to make their selfies more appealing & $62.4 \%$ \\
\hline Confessed to "very often" feeling addicted to selfie-taking & $58.4 \%$ \\
\hline Tried to achieve a certain body type or look to gain more popularity from their selfie-taking & $26.1 \%$ \\
\hline Took selfies preferably when they were looking good or dressed up for a special occasion & $84.7 \%$ \\
\hline Copied/Imitated the selfies taken by celebrities & $22.5 \%$ \\
\hline Felt confident while posting their selfies online & $54.5 \%$ \\
\hline Checked "very often" for the likes and comments related to their selfies on social network sites & $61.7 \%$ \\
\hline Clicked selfies in public places & $78.2 \%$ \\
\hline
\end{tabular}


outfits, make-up, poses, and places. For example, Balakrishnan and Griffiths (2018) found that adolescents have varying motives for selfie-taking, some of which were more personally oriented, such as creating memories or enhancing their mood. These motives may also account for the higher frequency of offline selfies by adolescents.

Because adolescents live in a digital world, selfportraits provide a way of participating and affiliating with that world. However, selfies can also inform emotional or behavioural problems, for example, the material that adolescents view online - selfies included - can be influential in moulding their sense of the self. This research has shown that adolescents make emotional connections to what they see are being posted online and that their behaviours and decisions are influenced by how the peers in their social networks are interacting. The answers below showcase that selfies are used to mould their sense of self:

"Selfies reflect the fashion style that I choose so it shows who I am." (Female adolescent no 8)

"For me, a selfie is a self-worth, it is how I become important. It feels like I can say to my friends, hi this is me." (Male adolescent no 11)

The adolescents indicated that they often felt envy, lonely, and generally worse about themselves after perusing their friends' social pictures. The following answers highlight the notion that adolescents experience an affective reaction to the imagined evaluation of others:

"I feel like I don't exist when my friends post photos of a party I wasn't invited to." (Female adolescent no 14)

"I know everybody is entitled to his or her own opinion, but I am unhappy if my friends don't like my selfie." (Male adolescent no 4)

"If my friends post negative comments on my selfie, I immediately delete my selfie." (Female adolescent no 21)

The above comments by the participating adolescents offer some insight into the effects of the looking-glass-self theory. According to Cooley (as cited in O' Brien, 2011), if others' evaluation of the actor is positive, the effect is positive, but if others' evaluation is negative, the effect is negative. In this case, viewing selfies posted on social media by peers could result in the participants experiencing low body confidence or a desire to change their appearance after comparing themselves with the posted images. This is in line with what the looking-glass-self theory offers toward understanding the roles of others in the development of self.

\section{DISCUSSION}

It is clear that selfies have the amazing power to say things that we cannot say, fill spaces that words cannot fill, and let us look at others and ourselves in a way that is deeply personal and unique. Jung argues that "everything that irritates us about others can lead us to understand ourselves" (Goodreads, 2018). Psychologically speaking, there may be some benefit to participating in sharing selfies, because this practice is interwoven with our social culture and a way to socially interact with others.

With my involvement in the community engagement project, Embrace our Children, I worked with adolescents. I sometimes encouraged or assigned specific self-portraits. Selfies can also be a window into deeper adolescent issues. In specific cases, where the adolescents find it hard to open up about issues, selfies could be a way for therapists to break the ice and start a dialogue about what the adolescent was feeling when the selfie was taken, or why he or she snapped the selfie in the first place. Increasingly, when I ask an adolescent to check their week, rather than launch a list of days, they will take their smartphone and show me a photo. The selfie can relate many things, like "look what I have accomplished", "look where I am", "look who I am with", "look how good I look", "look how ironic I can be", or even "look how I am feeling". Selfies permit direct non-verbal self-confrontation. It can therefore not only be validating and empowering but also the most threatening and risky kind of photos to open up one's emotions.

\section{CONCLUSION}

This research study is one of only a few in South Africa regarding selfie-taking by adolescents and provides a new means of analysing selfie behaviour among adolescents. This study also complements previous qualitative findings on selfie behaviours (McLean, Jarman \& Rodgers, 2019). The adolescents in this study had a positive outlook on the concept of 
selfies as well as selfie-taking. Taking a selfie can also inhabit a role that the adolescent wants to take on, but have not yet done so. For example, one of the adolescents said that he wanted to learn to play the piano and take a photo of himself sitting in front of an open piano. This can serve as an inspirational reminder.

However, even though taking selfies is a part of growing up digitally, it does not mean that all selfportraits are always good. Like with all behaviours that children and adolescents try out, parents should help them to learn the limits and guidelines about which types of photos are acceptable and which are not. It is not likely that adolescents would think beyond seeing their images as a sort of developmental skin that they try on and then shed again, but they do need to be aware that all their actions in this regard have consequences.

This research also answers the question: Do selfies make adolescents self-conscious? The act of taking a selfie could make adolescents self-conscious and more aware of how others view them. This may occur because the act forces them to focus on themselves, much like looking in a mirror. This is in line with what the looking-glass-self theory offers: People use the self as a mirror, and nowadays, selfies are being utilised as mirrors (Cooley, 1902).

I am sure that the psychiatrist and archetype pioneer Carl Jung would be fascinated by the images appearing on the social radar these days. No doubt, Jung would interpret this as a shadow period of human consciousness. He identifies the shadow as a primary personality archetype, universal to humankind. The shadow does not only represent darkness, as the name implies but a fundamental split in the early human psyche. The shadow archetype is a wild thing, the dark potential within us that we fear and dare not become (Martin, 2015). Instead of burying it and tamping it down, Jung believes that the shadow must be acknowledged, met head-on, and integrated into the psyche to become whole -to wake us up so that we can transform the darkness (Martin, 2015). It, therefore, turns out that selfies can have a positive impact on adolescents' self-esteem - that is, if they approach taking and posting them with the right attitude. Although spending too much time on social media is still proving to be bad for one's self-esteem, taking selfies, on the other hand, might have the opposite effect.
As is so often the case with academic endeavours, this research raises more questions than necessarily providing conclusive answers regarding attitudes toward selfie-taking and the effects of selfies on adolescents. However, it raises some interesting questions about the effects of selfie-taking. Taking selfies is often viewed as the epitome of selfcenteredness, and selfie-taking is, in fact, modestly correlated with narcissism. I also found myself challenged to, indeed, perceive the selfie as a potentially valuable tool for exploration and expression, and perhaps as potent, creative, and powerful, thus considering resilience and the contributions of positive psychology. Nevertheless, taking selfies could make people self-conscious. The mere act of taking a selfie can cause adolescents to view themselves through the eyes of others and make them more sensitive to others' reactions.

If our current technological environment has psychological effects on adolescents, it is scary to think about what the future may hold. If there are psychological effects associated with the selfie, particularly on an adolescent's self-esteem, then there is a great impetus to research this topic further. Investigating how selfies can be used positively, as identity exploration, for fun, or to increase self-esteem, would be highly useful. Perhaps you, too, will be moved to reconsider your current related thinking and preconceived ideas and further pioneer efforts in understanding and improving the lives of adolescents in whichever way is most suited to your context.

\section{REFERENCES}

Academy of Ideas. (2015, December 17). Carl Jung and the Shadow: The Hidden Power of our Dark Side. Retrieved from http://academyofideas.com/2015/12/carl-jung-and-theshadow-the-hidden-power-of-our-dark-side/

Balakrishnan J, Griffiths M.D. (2018). An exploratory study of "selfitis" and the development of the Selfitis Behavior Scale. Int $\mathrm{J}$ Ment Health Addict., 16(3), 722-736. https://doi.org/10.1007/s11469-017-9844-x

Barry, C.T., Doucette, H., Loflin, D.C., Rivera-Hudson, N., \& Herrington, L.L. (2017). 'Let me take a selfie': Association between self-photography, narcissism and self-esteem. Psychology of Popular Media Culture, 6(1), 48-60. https://doi.org/10.1037/ppm0000089

BBC News Magazine. (2013, 7 June). Self-portraits and Social Media: The Rise and The 'Selfie".

Retrieved from http://www.bbc.co.uk/news/magazine-22511650.

Berg, B.L. (2009). Qualitative Research Methods for the Social Sciences $7^{\text {th }}$ edition. Boston: Pearson Education.

Bold, A, (2016, May 20). People who take a large number of "selfies" tend to overestimate how good looking and likable they are, a new study has found. Retrieved from http://www.telegraph. co.uk/science/2016/05/20/people-who-take-selfies-regularlyoverestimate-how-attractive-th/ 
Brin, J.G. (September 1, 2017). I'm Still Here: Saving The Work Of Robert Cornelius. Retrieved from https://hiddencityphila.org/ 2017/09/im-still-here-saving-the-work-of-robert-cornelius/

Chae, J. (2017). Virtual makeover: Selfie-taking and social media use increase selfie-editing frequency through social comparison. Computers in Human Behaviour, 66, 370-376. https://doi.org/10.1016/j.chb.2016.10.007

Chua, T.H.H., \& Chang, L. (2016). Follow me and like my beautiful selfies: Singapore girls' engagement in self-presentation and peer comparison on social media. Computers in Human Behaviour, 55, 190-197. https://doi.org/10.1016/j.chb.2015.09.011

Cooley, C. H. (1902). Human nature and the social order. New York: Scribner's Sons.

Cravens, H. (2006). The historical context of G. Stanley Hall's Adolescence (1904). History of Psychology, 9, 172-185. https://doi.org/10.1037/1093-4510.9.3.172

Diamond, S.A. (2012, April 20). Essential Secrets of Psychotherapy: What is the "Shadow"? Understanding the "dark side" of psyche. Retrieved from https://www.psychologytoday.com/ blog/evil-deeds/201204/essential-secrets-psychotherapywhat-is-the-shadow

Dutta E, Sharma P, Dikshit R, et al. (2016). Attitudes toward selfie taking in school-going adolescents: an exploratory study. Indian J Psychol Med., 38(3), 242-245. https://doi.org/10.4103/0253-7176.183094

Ellison, N., Heino, R., \& Gibbs, J. (2006). Managing Impressions Online: Self-Presentation processes in the online dating environment. Journal of computer-mediated communication, 11(2), 415-441. https://doi.org/10.1111/j.1083-6101.2006.00020.x

Glum, J. (2015, September 22). Millennials selfies: Young adults will take more than 25,000 pictures of themselves during their lifetimes. International Business Times. Retrieved from http://www.ibtimes.com/millennials-selfies-young-adults-willtake-more-25000-pictures-themselves-during-2108417

Goodreads Inc. (2018). Jung quotes. Retrieved from https://www.goodreads.com/author/quotes/38285.C_G_Jung

Hall, G. S. (1904). Adolescence: Its psychology and its relations to physiology, anthro-pology, sociology, sex, crime, religion, and education (Vols. I \& II). New York: D. Appleton \& Co. https://doi.org/10.1037/10618-000

Hanson, O. (2018, October 13). Criminals Who Couldn't Help But Pause to Take a Selfie. Retrieved from https://www.ranker. com/list/wrongdoer-selfies/oliverhanson

Hardey, M. (2015). The UK's Instagram Changing Economy \& Cultural Landscape: The Sharp Rise, In Professional Instagram users As Share of Images; Affiliation And Other Revenues Continue To Grow. Project Report. Mariann. Hardey, Durham University.

Hayes, M., \& van Stolk-Cooke, K., \& Muench, F. (2015). Understanding Facebook use and the psychological affects of use across generations. Computers in Human Behaviour, 49(C), 507-511. https://doi.org/10.1016/j.chb.2015.03.040

Hennink, M., Hutter, I., \& Bailey, A. (2011). Qualitative research methods. London, England: Sage Publications.

Hines, B. (2016, January). Negative effects of social media: "The selfie". Retrieved from https://storify.com/Brennahines/ negative-effects-of-social-media

Independent life-style (March 29, 2019). Twitter then and now: How the site has changed since its launch in 2006. Retrieved from https://www.independent.co.uk/life-style/twitter-launch-firsttweets-jack-dorsey-ceo-a8846261.html

Jacobus, M. (2005). The Poetics of Psychoanalysis. London: Oxford p. 160.

Jacoby, M. (2017). Shame and the Origins of Self-Esteem: A Jungian approach (Routledge Mental Health Classic Editions) 1st Ed. New York: Routledge. ISBN-13: 978-1138120211
Jung, C.G. (1969). The collected works. Vol 11. Psychology and Religion: West and East. 2nd ed. New Jersey: Princeton University Press p.131. ISBN-13: 978-0691097725

Jung, C. G. (1947, revised 1954). On the Nature of the Psyche. London: Ark Paperbacks.

Jung, C.G. 1948. The phenomenology of the spirit in fairy tales. The archetypes and the collective unconscious. Vol 9 (Part 1), 207-254.

Klein, J. (2006). Our Need for Others and its roots in infancy. New York: Routledge pp. 229-289. eBook ISBN-13: 9781138410367 https://doi.org/10.4324/9780203136591

Lamia, M.C. (2010, September 24). Your Sense of Agency: Are You in Control of Your Life? Reprieved from https://www. psychologytoday.com/za/blog/the-white-knightsyndrome/201009/your-sense-agency-are-you-in-controlyour-life\#: :text=Having $\% 20 \mathrm{a} \% 20$ sense $\% 20$ of $\% 20$ agency,face $\% 20$ of $\% 20$ conflict $\% 20$ or $\% 20$ change.\&text $=$ You $\% 20$ can $\% 20$ begin $\% 20$ to $\% 20$ work,be $\% 20$ effective $\% 20$ in $\% 20$ your $\% 20$ life.

Lerner, R. M., \& Steinberg, L. (2009). The scientific study of adolescent development: Historical and contemporary perspectives. In R. M. Lerner, L. Steinberg (Eds.), Handbook of adolescent psychology, Vol 1: Individual bases of adolescent development (3rd ed.) (pp. 3-14). New Jersey, $\mathrm{NJ}$ : John Wiley \& Sons Inc.

https://doi.org/10.1002/9780470479193.adlpsy001002

Martin, R.N. (June 10, 2015). What Do Selfies, Vampires and Zombies Have in Common? Retrieved from https://www.huffpost.com/entry/what-do-selfies-vampires_b_7036626

Mascheroni, G., Vincent, J., \& Jimenez, E. (2015). "Girls are addicted to likes so they post semi-naked selfies": Peer mediation, normativity and the construction of identity online. Cyberpsychology: Journal of Psychosocial Research on Cyberspace, 9(1). https://doi.org/10.5817/CP2015-1-5

McGuire, W. (Ed.). (1974). The Freud/Jung Letters - The correspondence between Sigmund Freud and C. G. Jung (1906 - 1914). New Jersey: Princeton University Press (pp.115-116). ISBN0-691-09-8905 Retrieved from https://archive.org/details/FreudJungLetters/page/n1

McLean S.A., Jarman H.K., \& Rodgers R.F. (2019). How do "selfies" impact adolescents' well-being and body confidence? A narrative review. Psychology Research and Behavior Management, 12, 513-521. https://doi.org/10.2147/PRBM.S177834

McLeod, S. (2014). Simply Psychology. Retrieved from https://www.simplypsychology.org/carl-jung.html

Minsky R (1996). Psychoanalysis and Gender London: Routledge (pp. 119-20).

Molloy, A. (2013, 24 December). Year of the Selfie: The Birth - and Death - of the 2013's Biggest Star Trend. Retrieved from http://www.independent.co.uk/news/people/news/year-of-theselfie-the-birth--and-death--of-the-years-biggest-star-trend9024534.html.

Nicholls, J. (2017). The Selfie. Learning about and making different types of photographic self portrait. Retrieved from http://www.photopedagogy.com/the-selfie.html

O' Brien, J.(ed). (2011). The Production of Reality: Essays and Reading on Social Interaction. California: Pine Forge Press

Park, N., Kim, Y., Shon, H.Y., \& Shim, H. (2013). Factors influencing smartphone use and dependency in South Korea. Computers in Human Behaviour, 29(4), 1763-1770. https://doi.org/10.1016/j.chb.2013.02.008

Pietkiewicz, I., \& Smith, J.A (2011). A practical guide to using interpretative phenomenological analysis in qualitative research. Psychological Journal, 18(2), 361-369. https://doi.org/10.14691/CPPJ.20.1.7 
Rad, M.R. (2011, September 2). Do You Know Your Shadow (Dark) Side? Retrieved from https://www.huffingtonpost.com/roya-rrad-ma-psyd/shadow-dark-side_b_945001.html

Re D. E., Wang S. A., He J. C., Rule N. O. (2016). Self indulgence: self-favoring biases in perceptions of selfies. Social Psychological and Personality Science 7(6), 1-9. https://doi.org/10.1177/1948550616644299

Ronning, D. (2015, March 17). The Selfie: Using Photography as a Form of Self Reflection. Retrieved from http://www.psychedinsanfrancisco.com/selfie-self-reflection/

Senft, M.T., \& Baym, N.K. (2015). What does the selfie say? Investigating a global phenomenon. International Journal of Communication, 9(19), 1588-1606. doi: 19328036/2015FEA0002
Sifferlin, A. (2013, 6 September). Why Selfies Matterdalam Social Media. Retrieved from http://healthland.time.com/2013/ 09/06/why-selfies-matter/.

Soerjoatmodjo, G. (2016). I Selfie Therefore I Exist: A Preliminary Qualitative Research on Selfie as Part of Identity Formation in Adolescents. Humaniora, 7, 139-148. https://doi.org/10.21512/humaniora.v7i2.3497

Webster, J., \& Tiggemann, M. (2003). The relationship between women's body satisfaction and self-image across the life span: The role of cognitive control. Journal of Genetic Psychology, 164(2), 241-252. https://doi.org/10.1080/00221320309597980

Young-Eisendrath, P. \& Hall, J.A. (1991). Jung's Self Psychology: A Constructivist Perspective. New York: Guilford Press. ISBN089862-553-X

Received on 16-07-2020

Published on 01-02-2021

DOI: https://doi.org/10.6000/1929-4409.2021.10.32

(c) 2021 Petro van der Merwe; Licensee Lifescience Global.

This is an open access article licensed under the terms of the Creative Commons Attribution Non-Commercial License (http://creativecommons.org/licenses/by-nc/3.0/) which permits unrestricted, non-commercial use, distribution and reproduction in any medium, provided the work is properly cited. 